POLLACK PERIODICA

An International Journal for Engineering and Information Sciences

DOI: $10.1556 / 606.2020 .15 .2 .4$

Vol. 15, No. 2, pp. 37-48 (2020)

www.akademiai.com

\title{
DESIGN OF LQR CONTROLLER FOR GAN BASED BUCK CONVERTER
}

\author{
${ }^{1}$ Miklos CSIZMADIA ${ }^{*}{ }^{2}$ Miklos KUCZMANN \\ ${ }^{1,2}$ Department of Automation, Széchenyi István University, Egyetem tér 1, H-9026 Győr \\ Hungary, email: ${ }^{1}$ csizmadia.miklos@sze.hu, ${ }^{2}$ kuczmann@sze.hu
}

Received 1 January 2019; accepted 10 September 2019

\begin{abstract}
This paper presents a design procedure of a switched-mode power converter, the well-known synchronous buck converter: the calculating method, and how to choose the parts of the converter are presented in detail, like the inductor, the capacitor and the semiconductors as well as the design of the state feedback. During the design process the efficiency and the high switching frequency are very important: the switching semiconductors are Gallium Nitride based. Then, a linear-quadratic regulator is designed and applied to the particular case of a buck converter.
\end{abstract}

Keywords: Switch mode power supply, Buck converter, State-space equation, Switch-mode power supplies, Linear quadratic regulator

\section{Introduction}

Nowadays the Switch-Mode Power Converters (SMPS) getting more and more attention, which are characterized by the high efficiency (and low losses), high power density, the wide input and output range, finally the small size and light weight [1], [2]. The operation mode of these converters is based on Pulse Width Modulation (PWM), resulting an easy way to control the output voltage. In addition, the SMPS can be stepup or step-down converters. Combining these positive advantages of the new semiconductor properties very high switching frequency and efficiency can be achievable. The high switching frequency means also lower ripple, however the sudden

${ }^{*}$ Corresponding Author 
changes in current $(d i / d t)$ or voltage $(d u / d t)$ generate higher order harmonics and the effect of parasitic inductances and capacities are not negligible. The next generation of the semiconductor devices, like Silicon Carbide ( $\mathrm{SiC})$ or Gallium Nitride $(\mathrm{GaN})$ gives new opportunities the design of the SMPS and control circuits.

\section{Operation and design of buck converter}

Buck converter is a type of non-isolated (Direct Current) DC/DC converters, which steps down the input voltage [3]. The non-isolated buck converter contains two semiconductors (transistor and diode) and energy storage elements (inductors and capacitors). The function of these elements is dual: they store the energy and have filter function. Nowadays, for the better efficiency the diodes are replaced by transistors having the same function, but better properties. This type of buck converters is called the synchronous buck converter in the literature [4].

The basic operation of the buck converter can be illustrated by looking at the two current paths represented by the states of the two switches (Fig. 1): SW1 is the highside switch and SW2 is the low side switch (diode). In the first period the high-side switch is turned on and the energy flows from input - through the LC filter - to the output. The energy in the inductor increases. In the second period high-side switch turn off and the low-side switch turned on. The energy from the inductor flows to the output, through SW2. Relevant, that at the same time just one semiconductor conducts; another one is off-state. Between the state-change a dead time has to apply avoiding the short circuit.

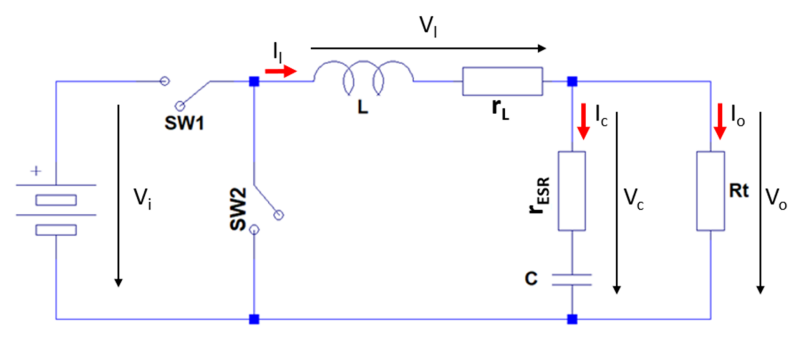

Fig. 1. Buck converter

In steady state, it can distinguish two operating mode, which depend on the current in the energy storage element (inductor):

- Continuous Conduction Mode (CCM);

- Discontinuous Conduction Mode (DCM).

In CCM the inductor current goes to zero in each switching period, in DCM the inductor sits with no current and no stored energy for part of the time.

The objective of this work is to design (and after that build up) a synchronous buck converter in CCM, because in the practice this solution is more common. The circuit of 
buck converter is shown in Fig. 1. This modeling method takes the parasite resistance of capacitor and inductor into consideration.

In the example, the input voltage of the buck converter is $48 \mathrm{~V}$, the output voltage is $12 \mathrm{~V}$, the output power is $100 \mathrm{~W}$, and the switching frequency is $1 \mathrm{MHz}$. The maximum allowable ripple current is $10 \%$ of the maximal output current, and the value of the voltage ripple is maximum $100 \mathrm{mV}$. Table I contains the additional parameters of the converter.

Table I

The parameter values used in the simulation of the buck converter

\begin{tabular}{|c|c|}
\hline Parameter & Value \\
\hline$d$ & 0.25 \\
$L$ & $10 \mu \mathrm{H}$ \\
$r_{L}$ & $21.8 \mathrm{~m} \Omega$ \\
$C$ & $10 \mu \mathrm{F}$ \\
$E S R$ & $5.7 \mathrm{~m} \Omega$ \\
$R_{t}$ & $1.2 \Omega$ \\
$T_{s}$ & $1 \mu \mathrm{s}$ \\
\hline
\end{tabular}

In steady-state the duty cycle is very important, which gives the ratio between the on time and the switching period and the ratio between outputs furthermore input voltage. It is denoted by $d$, accordingly [4]:

$$
d=\frac{v_{o}}{V_{i}},
$$

where $V_{o}$ is the output voltage and $V_{i}$ is the input voltage of the converter. The value of the output current can be calculated by using the output power and the output voltage:

$$
I_{o}=\frac{P_{o}}{V_{o}},
$$

where $I_{o}$ is the output current and the $P_{o}$ is the output power of the converter.

Inductors can be manufactured in various materials typically with a tolerance of $\pm 20 \%$. Inductors have an inherent DC resistance $\left(r_{\mathrm{L}}\right)$, which impacts the performance of the output stage. Minimizing the Direct Current Resistance (DCR) improves the overall efficiency of the converter. There is a trade-off between inductance and ripple current: the lower inductance causes higher ripple through the inductor, typically $10-30 \%$ of the maximum output current. In this case the value of ripple current has been defined. The value of the inductor can be calculated [4]:

$$
L=\frac{\left(V_{i}-V_{o}\right)}{\Delta I_{L}} t_{o n}=\frac{\left|-V_{o}\right|}{\Delta I_{L}} t_{o f f},
$$

where $\Delta I_{L}$ is the ripple current through the inductor, $t_{o n}$ is the on time of the semiconductors and the $t_{\text {off }}$ is the off time of semiconductor. 
The output capacitor $C_{\text {OUT }}$ maintains the regulated output voltage during the times when the inductor current is higher or lower than the output current, therefore the role of this part is very important. Each capacitor has an Equivalent Serial Resistance (ESR), which comes from the physical design. This parameter is very important in case of the design of regulators, because it influences the response time of the feedback loop and is also one component of the output voltage ripple. Choosing of the value of the capacitor requires great care. The minimal value of the capacitor can be calculated as [4]:

$$
C_{\min }=\frac{\Delta I_{L}}{8 f_{S w}\left(\Delta V_{\text {outmax }}-\Delta I_{L} E S R\right)},
$$

where $f_{s w}$ is the switching frequency and $\Delta V_{\text {outmax }}$ is the output voltage ripple through the output capacitor.

\section{State-space equations}

There are lots of modeling methods, which describe the behavior of the system e.g. the DQ-form [5], the state-space equations. The method of state-space describes the system with the state variables, which can be the voltage across the capacitor and the current through the inductor. These equations are first-order differential equations. In case of switching converters, these equations should be linearized, so they approximate the switching converter as a continuous linear system. In case of linear, causal and invariant Single-Input Single Output (SISO) system the state-space model can be descried by [6]:

$$
\begin{aligned}
& \frac{d \mathbf{x}(t)}{d t}=\mathbf{A x}(t)+\mathbf{b} s(t), \\
& y(t)=\mathbf{C}^{T} \mathbf{x}(t),
\end{aligned}
$$

where $\mathbf{x}(t)$ is the state vector; $s(t)$ is the input; $y(t)$ is the output; $\mathbf{A}$ is the system matrix; $\mathbf{b}$ is the input vector; $\mathbf{C}^{T}$ is the output vector.

The system matrix $\mathbf{A}$ is $N \mathrm{x} N$-order quadratic matrix.

According to Kirchhoff's law, the following equations can be written [7]:

$$
v_{C}+r_{E S R} C \frac{d v_{C}}{d t}=V_{o}=R_{t}\left(i_{L}-C \frac{d v_{C}}{d t}\right),
$$

and

$$
r_{L} i_{L}+L \frac{d i_{L}}{d t}=V_{i}-V_{o}=V_{i}-R_{t}\left(i_{L}-C \frac{d v_{C}}{d t}\right) .
$$

The of output voltage is the following:

$$
V_{o}=\frac{R_{t} r_{E S R}}{R_{t}+r_{E S R}} i_{L}+\frac{R_{t}}{R_{t}+r_{E S R}} v_{C}
$$


When SW1 is turned on (and SW2 is turned off), conducts for a ratio $d$ of a period. The state matrix at the state $t_{o n}$ is, from (6), (7) and (8):

$$
\begin{aligned}
& {\left[\begin{array}{c}
\frac{d i_{L}}{d t} \\
\frac{d v_{C}}{d t}
\end{array}\right]=\left[\begin{array}{cc}
-\frac{\left(R_{t} r_{L}+r_{E S R} r_{L}+r_{E S R} R_{t}\right)}{L\left(R_{t}+r_{E S R}\right)} & -\frac{R_{t}}{C\left(R_{t}+r_{E S R}\right)} \\
\frac{R_{t}}{C\left(R_{t}+r_{E S R}\right)} & -\frac{1}{C\left(R_{t}+r_{E S R}\right)}
\end{array}\right]\left[\begin{array}{c}
i_{L} \\
v_{C}
\end{array}\right]+\left[\begin{array}{l}
1 \\
L \\
0
\end{array}\right] V_{i},} \\
& =\mathbf{A}_{o n} \mathbf{x}+\mathbf{b}_{o n} S \\
& V_{o}=\left[\begin{array}{ll}
\frac{R_{t} r_{E S R}}{R_{t}+r_{E S R}} & \frac{R_{t}}{R_{t}+r_{E S R}}
\end{array}\right]\left[\begin{array}{l}
i_{L} \\
v_{C}
\end{array}\right]+\left[\begin{array}{l}
0 \\
0
\end{array}\right] V_{i}=\mathbf{C}_{o n}^{T} \mathbf{x} .
\end{aligned}
$$

When SW1 is turned off, SW2 conducts for a ratio of (1-d) of a period. The state space equation can be written as ( $t_{\text {off }}$ state matrix):

$$
\begin{aligned}
& {\left[\begin{array}{c}
\frac{d i_{L}}{d t} \\
\frac{d v_{C}}{d t}
\end{array}\right]=\left[\begin{array}{cc}
-\frac{\left(R_{t} r_{L}+r_{E S R} r_{L}+r_{E S R} R_{t}\right)}{L\left(R_{t}+r_{E S R}\right)} & -\frac{R_{t}}{C\left(R_{t}+r_{E S R}\right)} \\
\frac{R_{t}}{C\left(R_{t}+r_{E S R}\right)} & -\frac{1}{C\left(R_{t}+r_{E S R}\right)}
\end{array}\right]\left[\begin{array}{l}
i_{L} \\
v_{C}
\end{array}\right]+\left[\begin{array}{l}
0 \\
0
\end{array}\right] V_{i}} \\
& =\mathbf{A}_{o f f} \mathbf{x}+\mathbf{b}_{o f f} S \\
& V_{o}=\left[\begin{array}{ll}
\frac{R_{t} r_{E S R}}{R_{t}+r_{E S R}} & \frac{R_{t}}{R_{t}+r_{E S R}}
\end{array}\right]\left[\begin{array}{l}
i_{L} \\
v_{C}
\end{array}\right]+\left[\begin{array}{l}
0 \\
0
\end{array}\right] V_{i}=V_{i} \mathbf{C}_{o f f}^{T} \mathbf{x} .
\end{aligned}
$$

Averaging the state-variable description [3]:

$$
\begin{aligned}
& \frac{d x(t)}{d t}=\left(\mathbf{A}_{o n} d+\mathbf{A}_{o f f}(1-d)\right) \mathbf{x}+\left(\mathbf{b}_{o n} d+\mathbf{b}_{o f f}(1-d)\right) s, \\
& y(t)=\left(\mathbf{C}_{o n}^{T} d+\mathbf{C}_{o f f}^{T}(1-d)\right) \mathbf{x} .
\end{aligned}
$$

Separating the variables:

$$
\begin{aligned}
& d=D+\tilde{d}, \\
& \mathbf{x}=\mathbf{X}+\tilde{\mathbf{x}},
\end{aligned}
$$

where small signal values are represented with a tilde and the steady state component by the uppercase letters. For example, $\widetilde{\boldsymbol{x}}$ is a small-signal variation in the DC or steadystate component $\boldsymbol{X}$.

The small signal state space description:

$$
\begin{aligned}
& \frac{d \widetilde{\boldsymbol{x}}(t)}{d t}=\mathbf{A} \tilde{\mathbf{x}}+\left(\left(\mathbf{A}_{o n}-\mathbf{A}_{o f f}\right) \mathbf{X}+\left(\mathbf{b}_{o n}-\mathbf{b}_{o f f}\right) V_{i}\right) \tilde{d} \\
& \tilde{v}_{o}=\mathbf{C}^{T} \tilde{\mathbf{x}}+\left(\mathbf{C}_{o n}^{T}-\mathbf{C}_{o f f}^{T}\right) \mathbf{X} \tilde{d} .
\end{aligned}
$$


The linearized and simplified model of the buck converter can be written as

$$
\left[\begin{array}{c}
\frac{d i_{L}}{d t} \\
\frac{d v_{C}}{d t}
\end{array}\right]=\left[\begin{array}{cc}
-\frac{\left(R_{t} r_{L}+r_{E S R} r_{L}+r_{E S R} R_{t}\right)}{L\left(R_{t}+r_{E S R}\right)} & -\frac{R_{t}}{C\left(R_{t}+r_{E S R}\right)} \\
\frac{R_{t}}{C\left(R_{t}+r_{E S R}\right)} & -\frac{1}{C\left(R_{t}+r_{E S R}\right)}
\end{array}\right]\left[\begin{array}{c}
i_{L} \\
v_{C}
\end{array}\right]+\left[\begin{array}{c}
\frac{d}{L} \\
0
\end{array}\right] V_{i}
$$

Substituting the values of Table $I$ it results in

$$
\mathbf{A}=\left[\begin{array}{ll}
-2747.3 & -99527.2 \\
99527.2 & -82939.4
\end{array}\right], \quad \mathbf{b}=\left[\begin{array}{c}
25000 \\
0
\end{array}\right]
$$

The transfer function of the system can be obtained, i.e.

$$
W(s)=\frac{141.8 s+2.488 \cdot 10^{9}}{s^{2}+8.569 \cdot 10^{4} s+1.013 \cdot 10^{10}} .
$$

The step response of the system without compensator between input and output voltage is shown in Fig. 2.

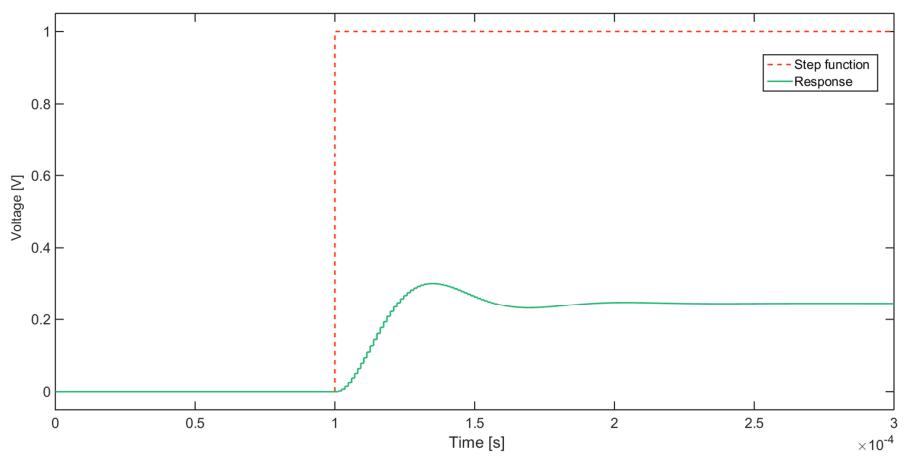

Fig. 2. Step response of the system without compensator

\section{Linear quadratic regulator design}

For regulatory purposes the Linear Quadratic Regulator (LQR) has been used. LQR is an optimal control, and type of a state feedback, which guarantees at least $60^{\circ}$ phase margin [8]. It can be used in case of SISO or Multiple-Input Multiple-Output (MIMO) system. For LQR design it is necessary the use the state space variable description (5). In addition, a functional with linear quadratic form can be defined by the general form:

$$
J(\mathbf{x}, \mathbf{u})=\frac{1}{2} \int_{0}^{T}\left[\mathbf{x}^{T} \mathbf{Q} \mathbf{x}+\mathbf{u}^{T} \mathbf{R} \mathbf{u}\right] d t
$$

where $\mathbf{Q}$ and $\mathbf{R}$ are the weighting matrices, $\mathbf{Q} \geq \mathbf{0}$, and $\mathbf{R}>\mathbf{0}$. The aim of an LQR strategy is to minimize the functional $J$. Because the aim is searching the minimum value of this functional, also the LQR gives the optimum value of control $\mathbf{u}$. 
It is very common, that the LQR system is augmented with an extra integrator [8], [9]: the derivative of this state is error, which is the difference between the output and the reference voltage. The modified block diagram of the closed loop system is shown in Fig. 3.

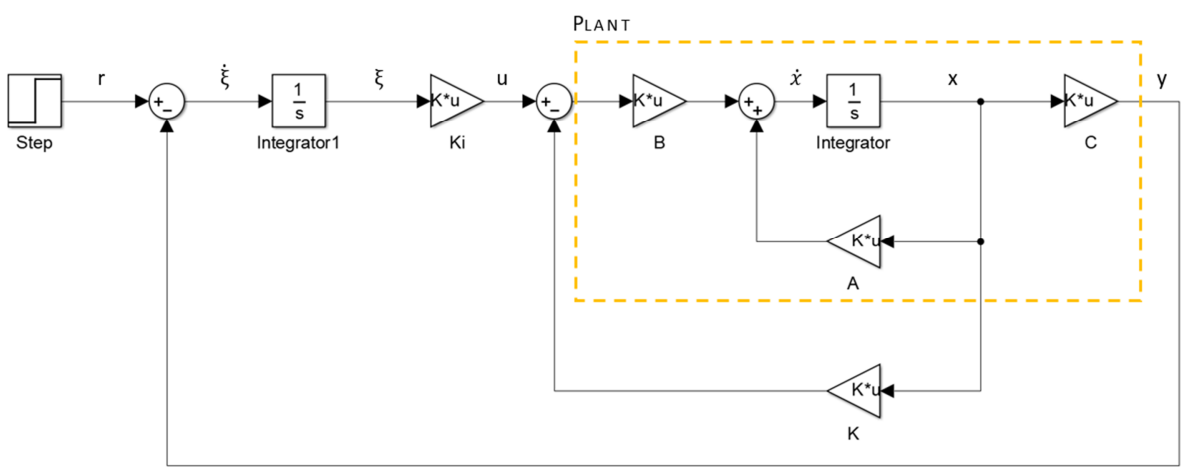

Fig. 3. LQR system with integrator

According to Fig. 3 the new state space matrices of the system can be describing [10] [11], [12].

$$
\frac{d x}{d t}=\widetilde{\mathbf{A}} \widetilde{\mathbf{x}}+\widetilde{\mathbf{B}} \widetilde{\mathbf{u}}, y=\tilde{\mathbf{C}}^{T} \tilde{\mathbf{x}},
$$

where

$$
\widetilde{\mathbf{A}}=\left[\begin{array}{cc}
\mathbf{A} & \mathbf{0} \\
-\mathbf{C}^{\mathrm{T}} & \mathbf{0}
\end{array}\right] \quad \tilde{\mathbf{b}}=\left[\begin{array}{l}
\mathbf{b} \\
\mathbf{0}
\end{array}\right], \quad \tilde{\mathbf{C}}^{T}=\left[\begin{array}{c}
\mathbf{C}^{T} \\
\mathbf{0}
\end{array}\right] .
$$

It is the designer's job to find the values of $\mathbf{Q}$ and the value of $\mathbf{R}$. There exist a lot of solutions and algorithms for this problem, which prefer different parameters of the system. To determine $\mathbf{Q}$ and $\mathbf{R}$ the energy-based design method have been used, which is described in [12] and [13]. The buck converter extended with an integrator is a thirdorder system therefore the matrices $\mathbf{Q}$ is a 3 by 3 matrix. $\mathbf{R}$ 's dimension is 1 because the controller can regulate just the duty cycle $(\tilde{d})$. Accordingly, the matrices have been set to be:

$$
\mathbf{Q}=\left[\begin{array}{ccc}
L I_{L}{ }^{2} & 0 & 0 \\
0 & C U_{C}^{2} & 0 \\
0 & 0 & C \cdot 10^{10}
\end{array}\right], \quad \mathbf{R}=1
$$

Solving the LQR problem with $[k, P, e]=\operatorname{lqr}(\tilde{\mathbf{A}}, \tilde{\mathbf{b}}, \mathbf{Q}, \mathbf{R})$ a function by Matlab the results is:

$$
\mathbf{K}=\left[\begin{array}{lll}
K_{1} & K_{2} & K_{i}
\end{array}\right]=\left[\begin{array}{lll}
2 & 1 & 20833
\end{array}\right] .
$$




\section{Simulation results}

The controller has also been tested in the frame of Matlab Simulink. The implementation of Buck converter is shown in Fig. 4, and the closed loop system with LQR controller is shown in Fig. 5 [14].

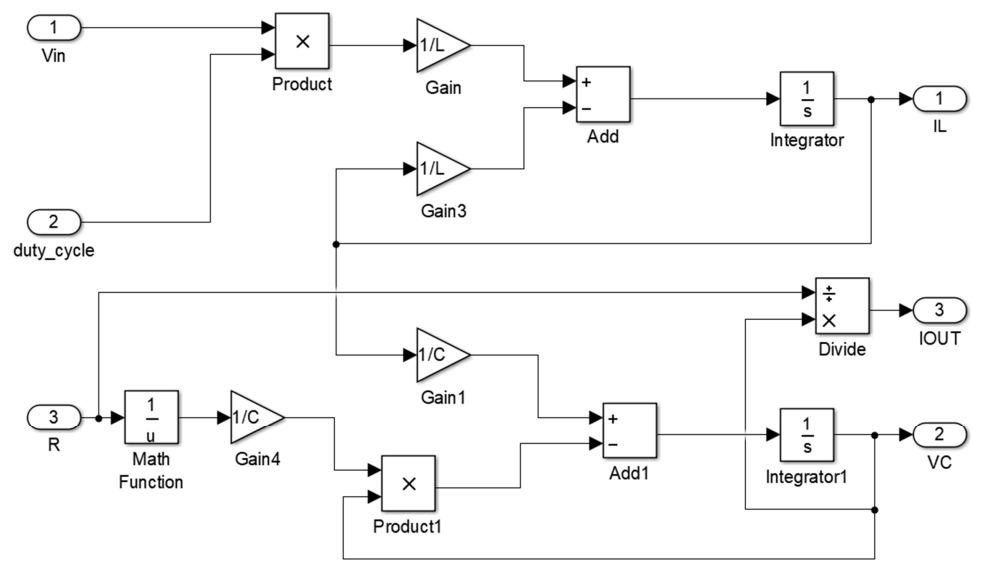

Fig. 4. Simulink Block model of Buck converter

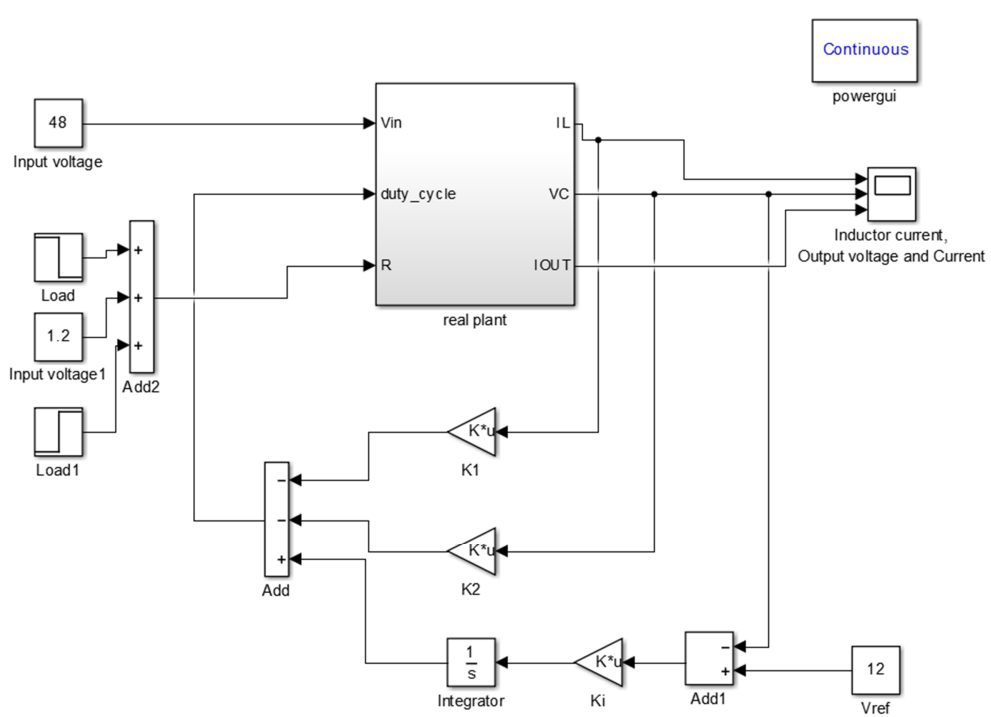

Fig. 5. Simulink model of controlled Buck converter

The converter is also tested with load disturbances: in $t=1.2 \mathrm{~ms}$ the load resistance is changed to $1.09 \Omega(10 \%$ higher output current), and $t=2 \mathrm{~ms}$ the output resistance and

Pollack Periodica 15, 2020, 2 
current are changed back to normal, 1.2 $\Omega$. In Fig. 6, the first plot shows the output resistance, the second is the output voltage and the third is the output current. The voltage overshoot, in case of $1 \mathrm{~A}$ overcurrent, is about $660 \mathrm{mV}$, and after $66 \mathrm{~ms}$ the output is stabilized.
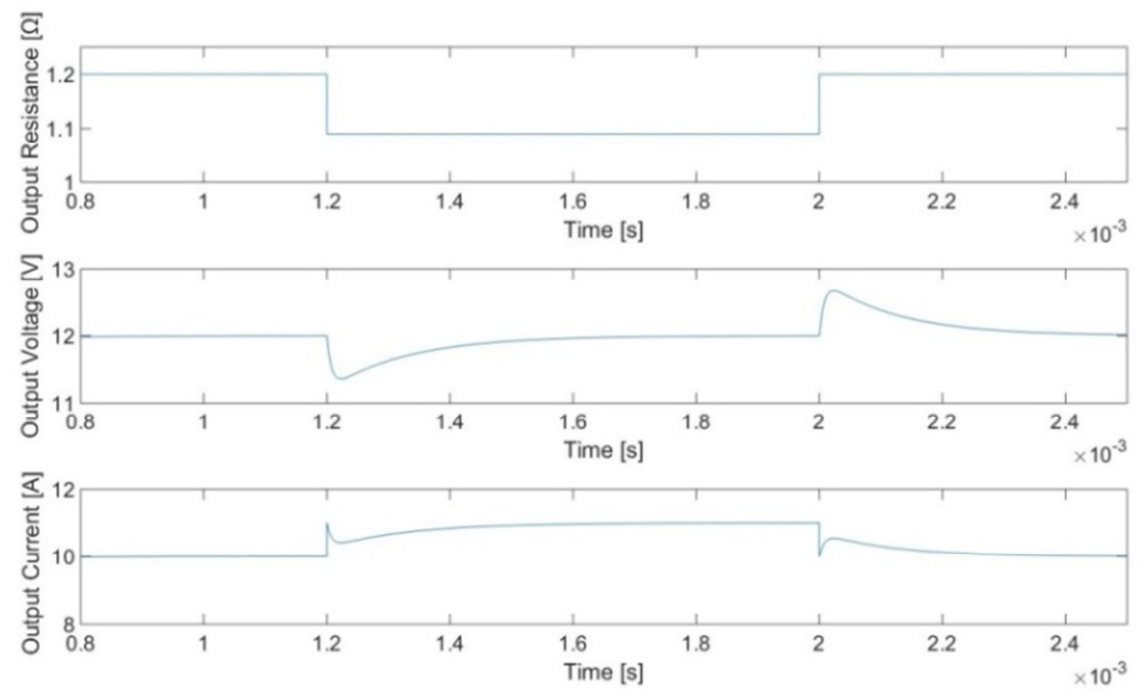

Fig. 6. Dynamic test of Buck converter

The Bode plot of the open loop system it shown in Fig. 7. The correct operation of the controller can be checked with the enough phase margins: in this case it is $86.7^{\circ}$.

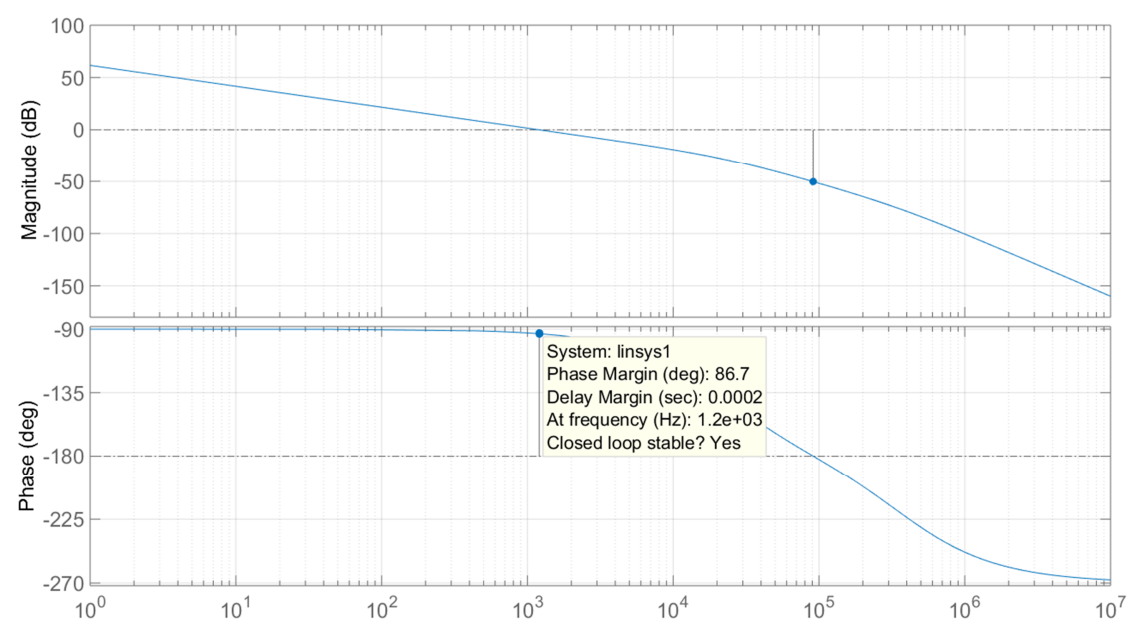

Fig. 7. Bode plot of Buck converter 
The open loop simulation results in LTSpice with semiconductor GaN E-HEMT (GS61008T) is shown in Fig. 8. The GaN based power electronics system can be exceeding the Si-system limits: reduce the energy cost, it is works on higher switching frequency (or on the same frequency it has lower loss) and it has better thermal and electrical properties [15]. To achieve good switching properties, separated turn-on and turn-off gate resistors are used. The turn on resistor is selected $10 \Omega$ and the off resistor is $1 \Omega$. The dead time between the high and low side signal is $25 \mathrm{~ns}$ [16]. Table II contains the important simulation results and in Fig. 9 the following simulation results are presented: the first plot shows the inductor current, the second plot shows the output voltage, the third plot shows the output current, the fourth plot shows the high side gate drive signal and the fifth plot shows the low side gate drive signal.

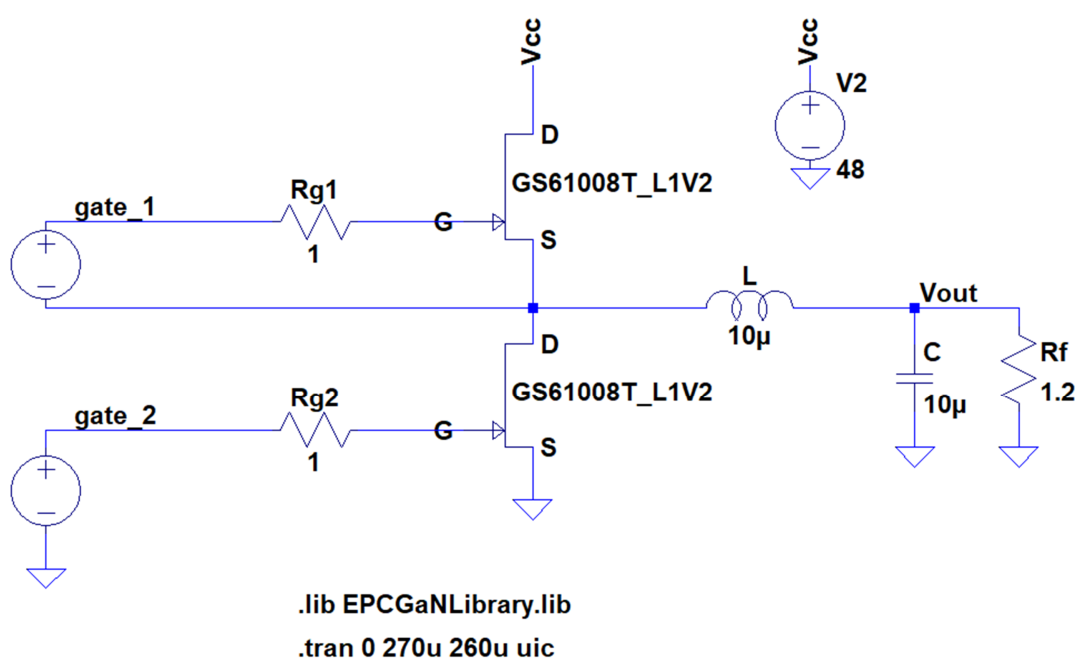

Fig. 8. Buck converter open loop circuit diagram in LTSpice

Table II

Buck converter simulation results

\begin{tabular}{|c|c|}
\hline Parameter & Value \\
\hline$D$ & 0.25 \\
$L$ & $10 \mu \mathrm{H}$ \\
$r_{\mathrm{L}}$ & $5.4 \mathrm{~m} \Omega$ \\
$C$ & $10 \mu \mathrm{F}$ \\
ESR & $5.7 \mathrm{~m} \Omega$ \\
$R_{\mathrm{t}}$ & $1.2 \Omega$ \\
$T_{\mathrm{s}}$ & $1 \mu \mathrm{s}$ \\
$P_{\text {loss T1 }}$ & $4.153 \mathrm{~W}$ \\
$P_{\text {loss } 2}$ & $746.45 \mathrm{~mW}$ \\
Total Efficiency & $97.58 \%$ \\
\hline
\end{tabular}


The role of electromagnetic compatibility (EMC) is very important in the design processes of SMPS especially for high frequency applications. Therefore, measuring this parameter is necessary in case of SMPS [17].

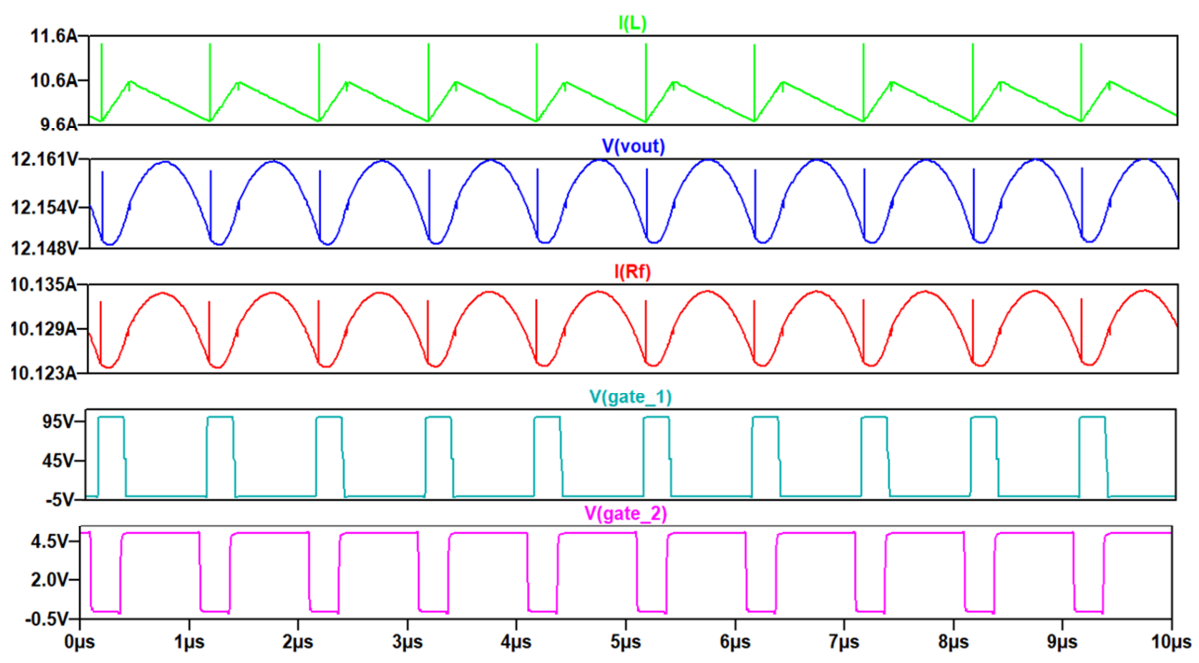

Fig. 9. LTSpice simulation results in steady state

\section{Conclusion}

A linear quadratic regulator controller has been designed for the Buck converter, which is based on the state feedback. The controller has been tested via Matlab and LTSpice. It is shown that this robust regulator can be realized easily. Next the circuit will be designed with GaN E-HEMT semiconductor and high frequency gate driver from Texas Instruments. The controller circuit will be designed in two ways: realized by passive components like operational amplifier, resistor and capacitor, and by digital controller.

\section{Open Access statement}

This is an open-access article distributed under the terms of the Creative Commons Attribution 4.0 International License (https://creativecommons.org/licenses/by/4.0/), which permits unrestricted use, distribution, and reproduction in any medium, provided the original author and source are credited, a link to the CC License is provided, and changes - if any - are indicated. (SID_1) 


\section{References}

[1] Hopkins A., McNeill N., Drury W. D., Atkins A. Deploying SiC BJTs in an 800-V switched-mode power supply for hybrid \& electric vehicles, 2017 IEEE $26^{\text {th }}$ International Symposium on Industrial Electronics, Edinburgh, UK, 19-21 June 2017, pp. 1430-1438.

[2] Maharjan M., Tandukar P., Bjracharya A., dos Reis F. B., Tamrakar U., Shrestha D., dos Reis F. S., Tonkoski R. SEPIC converter with wide bandgap semiconductor for PV battery charger, Brazilian Power Electronics Conference, Juiz de Fora, Brazil, 19-22 November 2017, 2018, pp. 481-486.

[3] Mohan N., Undeland T. M., Robbins W. P. Power electronics; converters, applications, and design, Wiley, 1995.

[4] Lee J. Basic calculation of a Buck converter's power stage, Richtek Application Note, AN041, 2015.

[5] Kelemen A., Kutasi N. Induction-heating voltage inverter with hybrid LLC resonant load, the D-Q model, Pollack Periodica, Vol. 2, No. 2, 2007, pp. 27-37.

[6] Kuczmann M. Signal and Systems (in Hungarian), Universitas, Győr, Hungary, 2005.

[7] Ahmed S. R., Noor N. J., Mostafa S. State space modeling of a Buck converter and design a controller, BSc Thesis, Brac University, Bangladesh, 2017.

[8] Rytkonen F. J., Tymerski R. Modern control regulator design for dc-dc converters, Portland State University, Electrical and Computer Engineering Department, 2005, pages 57.

[9] Keviczky L., Bars R., Hetthéssy J., Bányász C. Control engineering, Széchenyi István University, Hungary, 2011.

[10] Ogata K. Modern control engineering, Prentice Hall, 2009.

[11] Lindiya S. A., Vijayarekha K., Palani S., Determistic LQR controller for DC/DC Buck converter, Biennial International Conference of Power and Energy Systems: Towards Sustainable Energy, Bangalore, India, 21-23 January 2016, pp. 428-433.

[12] Stumpf P., Peschka A., Kurucsó B. Design of a quadratic boost converter, National Scientific Student's Associaton, Budapest, Hungary, 25-27 Marc 2015, pp. 25-28.

[13] Arango E., Ramos-Paja C. A., Calvente J., Giral R., Serena S. Asymmetrical interlaved DC/DC switching converters for photovoltaic and fuel cell applications, Part 1, Circuit generation, analysis and design, Energies, Vol. 5, No. 11, 2012, pp. 4590-4623.

[14] Alkrunz M., Yazici I. Design of discrete time controllers for the DC-DC boost converter, Sakarya Üniveristesi Fen Bilimeri Enstitüsü Dergisi Sakarya University Journal of Science, 2016, pp. 75-82.

[15] Csizmadia M. and Kuczmann M., Power Semiconductor Trends in Electric Drive Systems, Acta Technica Jaurinensis, Vol. 12, No. 1, pp. 13-25.

[16] Gan Systems, Design with GaN enhancement mode HEMT, Application Guide.

[17] Istók R., Kádár P. EMC measurement systems and noise suppression methods for LED laps and RF lighting controls, Pollack Periodica, Vol. 11, No. 3, 2016, pp. 141-152. 